\title{
Poor Vitamin D Status in Healthy Populations in India: A Review of Current Evidence
} Geeta Trilok Kumar ${ }^{1}$, Reema Chugh ${ }^{1}$, and Manfred Eggersdorfer ${ }^{2}$

${ }^{1}$ Department of Biochemistry, Institute of Home Economics, University of Delhi, India ${ }^{2}$ DSM Nutritional Products Ltd, Kaiseraugst, Switzerland

Received: January 15, 2015; Accepted: August 12, 2015

\begin{abstract}
Vitamin D deficiency is associated with rickets in children, with osteoporosis in the elderly, is thought to increase the risk of certain cancers and of cardiovascular diseases, and may have an impact on many other health conditions. Asians are reported to have a poor vitamin D status despite adequate sunshine in their regions. Data on the extent of vitamin D deficiency at the population level from most Asian countries, including India, are limited. Part of the reason for paucity regarding vitamin D status is the absence of clear recommendations on optimal vitamin D intakes and status, as well as clear consensus on the cut-offs for deficiency. With a large country covering several latitudes, ethnicities, cultures, traditions, and attitudes, the current data on vitamin D status in India is inadequate and classified in different ways, making interpretation difficult, and is unrepresentative as it comes only from four states, with about half the data from Delhi. Poor vitamin D status is almost universally reported across all age groups with as many as $95.7 \%$ neonates, $75 \%$ adults and $67 \%$ pregnant women having serum 25 hydroxy vitamin D levels $<50 \mathrm{nmol} / \mathrm{L}$ (deficient). Children and adults exposed to sunlight, living in rural or less polluted areas have been reported to have a better vitamin D status, especially in summer months. Lack of conclusive information emphasizes the need for state-specific data on the vitamin D status and the extent of sun exposure to issue recommendations for vitamin D intake in the country.
\end{abstract}

Key words: vitamin D, vitamin D status, 25-hydroxy vitamin D, 25(OH)D, India, population, prevalence

\section{Introduction}

Vitamin D has been recognized for several decades for its role in growth and maintenance of the skeletal system as well as for the regulation of serum calcium levels. Its deficiency has been known to cause improper bone mineralization, resulting in rickets in children and osteopenia in adults. Recent scientific evidence indicates an emerging role for vitamin $\mathrm{D}$ in a variety of physiological functions, including cell differentiation, insulin production, and immune function [1]. Next to the established role of vitamin D in bone mineralization and muscle strength, inadequate status may be associated with increased risk of high blood pressure [2], infectious diseases including tuberculosis [3], some cancers, multiple sclerosis, cardiovascular disease, type I diabetes, neurodevelopmental disorders, and several other health conditions [4-7].

The interest in vitamin D status has increased substantially over the past decade because of the many roles of vitamin D in physiological functions; the reported worldwide prevalence of vitamin $\mathrm{D}$ deficiency [8-10] including countries with sufficient sunshine and lack of enough evidence on the impact of inadequate 
and deficient status on public health. In Asia, vitamin $\mathrm{D}$ deficiency is widespread and a prevalence of more than $70 \%$ deficiency has been reported in the general Indian population [11]. Although there is no national data describing the extent of vitamin $\mathrm{D}$ deficiency in India, studies conducted in various regions of the country across all age groups indicate poor vitamin D status. Historically, the main source of vitamin D for Indians has always been via synthesis in the skin resulting from exposure to UVB light from the sun. Lack of sun exposure due to lifestyle changes, darker skin colour, high pollution levels, overcrowded residences with very little or no sunlight and almost no consumption of foods containing vitamin D are some of the risk factors for a poor vitamin D status in the healthy Indian population.

This review aims to collate the current data available on vitamin D status in the healthy population and to understand the extent of vitamin D deficiency in India across all age groups.

\section{Methods}

\section{Criteria for identification and selection of studies}

To identify relevant articles, we searched Pubmed and EmBase databases for terms such as vitamin D, vitamin D deficiency and prevalence, hypovitaminosis D, cross-sectional studies, vitamin D status, bone mineral density, and India. We restricted the search to selected peer-reviewed articles in English from 2000 to 2015 (as of 28 February 2015) conducted on apparently healthy populations reporting serum or plasma $25(\mathrm{OH}) \mathrm{D}$ levels. We excluded case control and randomized controlled studies and case reports. Baseline vitamin D levels in observational studies conducted on healthy populations were included (Figure 1).

\section{Vitamin D status}

The most well-accepted indicator of vitamin $\mathrm{D}$ status in humans is the level of $25(\mathrm{OH}) \mathrm{D}$ in serum or plasma and it is traditionally used to measure vitamin D status. There is, however, no worldwide consensus on the levels of $25(\mathrm{OH}) \mathrm{D}$ that are adequate or optimal for maintenance of bone health or for other health-related outcomes, and various studies have used different cut-offs for deficiencies. Lips classified the 25-hydroxyvitamin D levels into four stages
$[12,13]$ : severe deficiency $(<12.5 \mathrm{nmol} / \mathrm{L})$, deficiency $(12.5-25 \mathrm{nmol} / \mathrm{L})$, insufficiency $(25-50 \mathrm{nmol} / \mathrm{L})$, repletion $(>50 \mathrm{nmol} / \mathrm{L})$. Subsequently, the U.S. Institute of Medicine (IOM) in 2011 suggested that an RDAs of $600 \mathrm{IU} / \mathrm{d}$ for ages $1-70$ years and $800 \mathrm{IU} / \mathrm{d}$ of vitamin $\mathrm{D}$ for ages 71 years and older that corresponded to a serum 25(OH)D level of at least $20 \mathrm{ng} / \mathrm{mL}(50 \mathrm{nmol} / \mathrm{L})$ was sufficient to meet the requirements for at least $97.5 \%$ of the population for bone health outcome [14, 15], indicating that $20 \mathrm{ng} / \mathrm{mL}(50 \mathrm{nmol} / \mathrm{L})$ of $25(\mathrm{OH})$ $\mathrm{D}$ was adequate. However, no recommendations were made on extraskeletal outcomes due to lack of enough evidence.

Subsequent to the IOM report, in the past few years, several studies on the role of vitamin D in skeletal and non-skeletal outcomes have been published and it is clear that the minimum level of serum $25(\mathrm{OH}) \mathrm{D}$ required for preventing non-skeletal diseases is higher than that for skeletal diseases [16]. However, the threshold for serum $25(\mathrm{OH}) \mathrm{D}$ levels that is sufficient for various non-skeletal outcomes is not yet clear. Although some recent reports suggest that thresholds for required serum $25(\mathrm{OH}) \mathrm{D}$ vary according to outcomes and subgroups [17] or are disease-dependent [16], more data from larger studies are needed to make any recommendations on preventive and therapeutic doses.

For the purpose of this review we have used Lips classification for severe deficiency, deficiency and insufficiency because many articles from India used these cut-offs. The $25(\mathrm{OH}) \mathrm{D}$ levels $<50 \mathrm{nmol} / \mathrm{L}$ were used as cut-offs for deficiency according to Lips classification. Although most studies that we selected had reported their results in $\mathrm{ng} / \mathrm{mL}$, we converted $25(\mathrm{OH})$ D levels from $\mathrm{ng} / \mathrm{mL}$ to $\mathrm{nmol} / \mathrm{L}$, which is currently the more accepted unit.

\section{Results}

A total of 41 studies that matched our selection criteria were selected. Vitamin D status of Indian children, adolescents, pregnant women, adults and elderly from lower as well as upper socioeconomic strata and from rural or urban areas are listed in the following tables (Tables I-III).

The data cover many parts of the country but are not representative for all states. Latitudes, where mentioned, have been reported in tables. Use of vitamin D supplements was either absent or not reported in the majority of the studies.

Vitamin D status of infants, children and adolescents could not be tabulated separately because the 


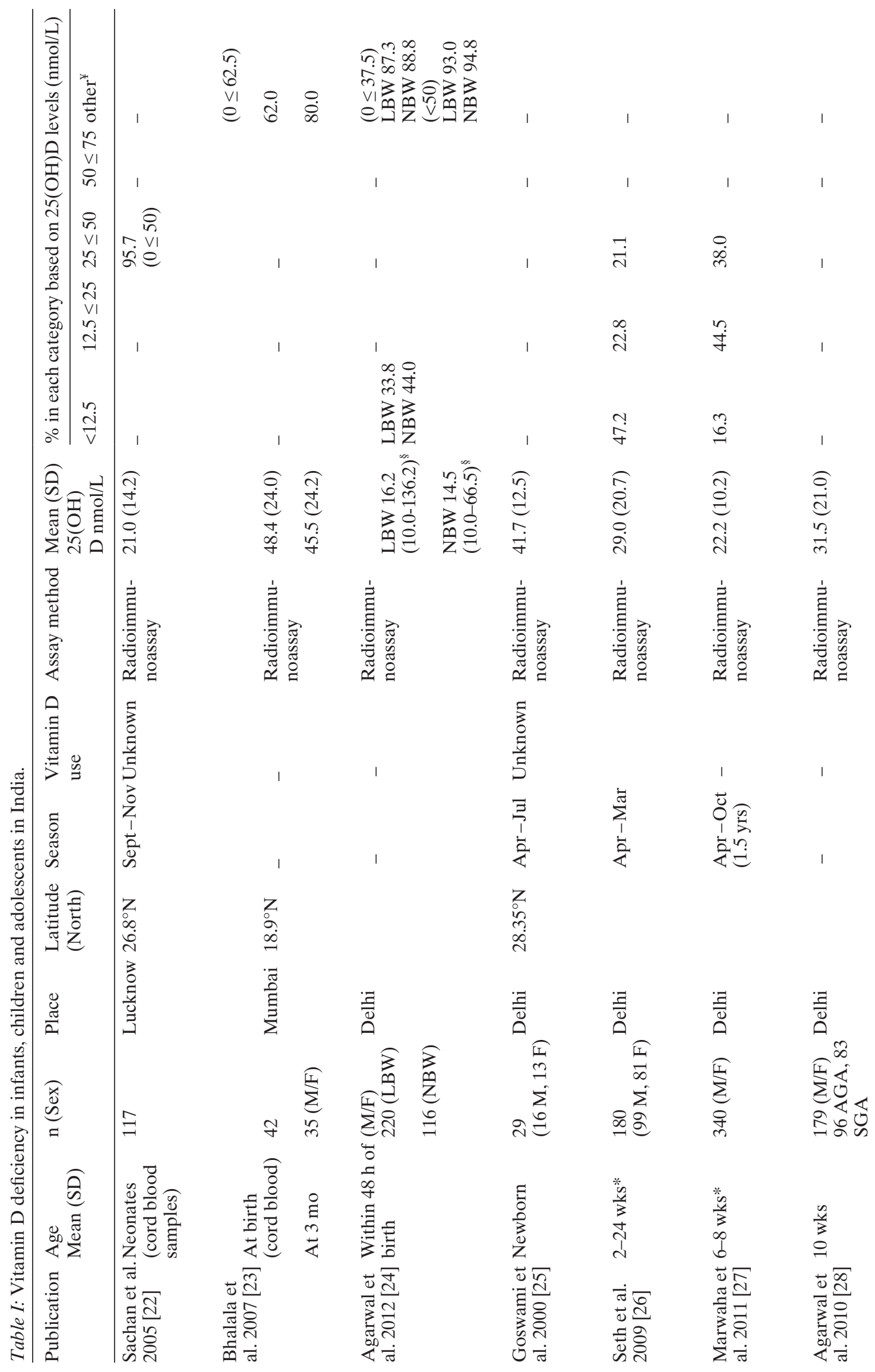




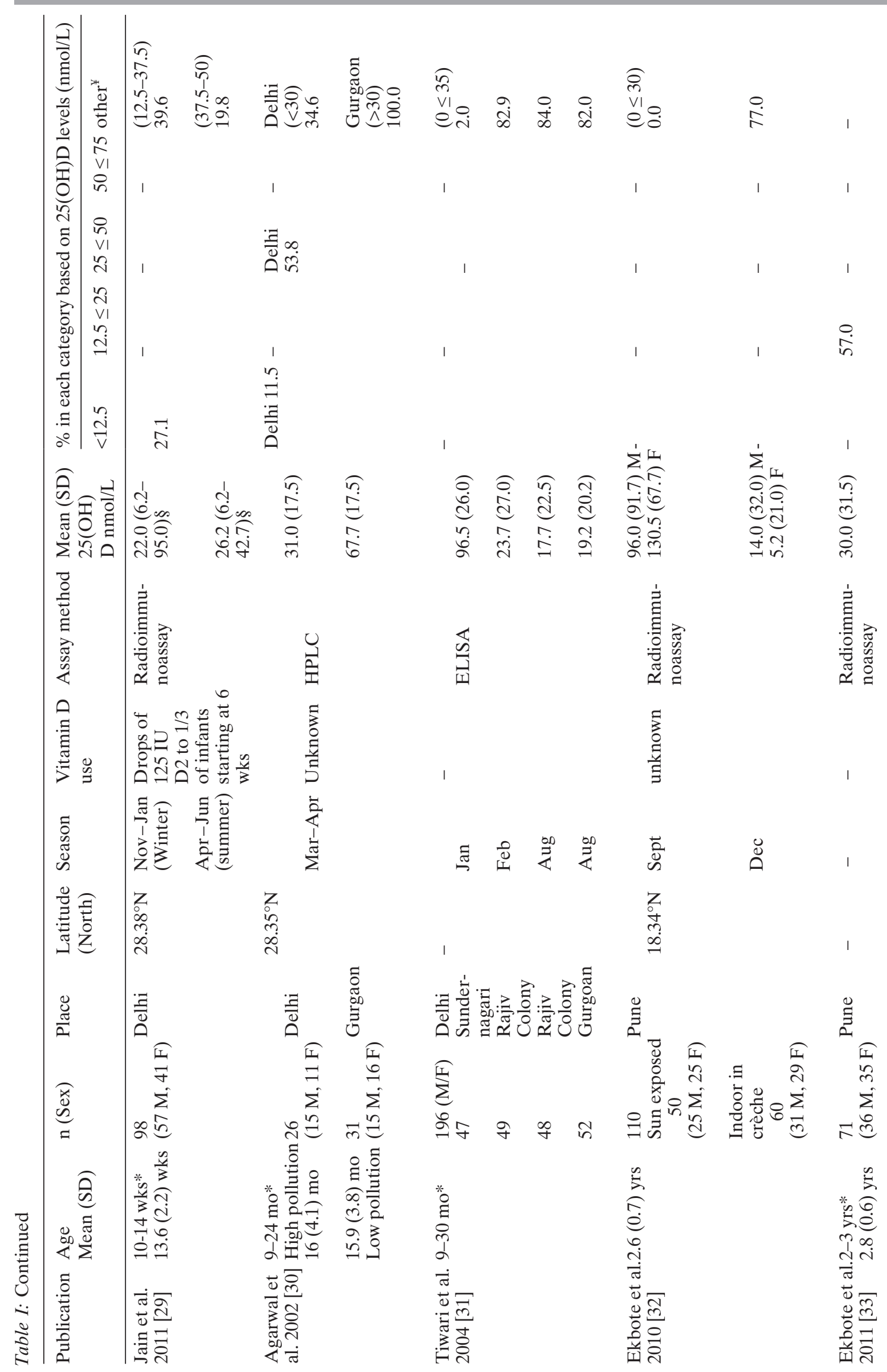




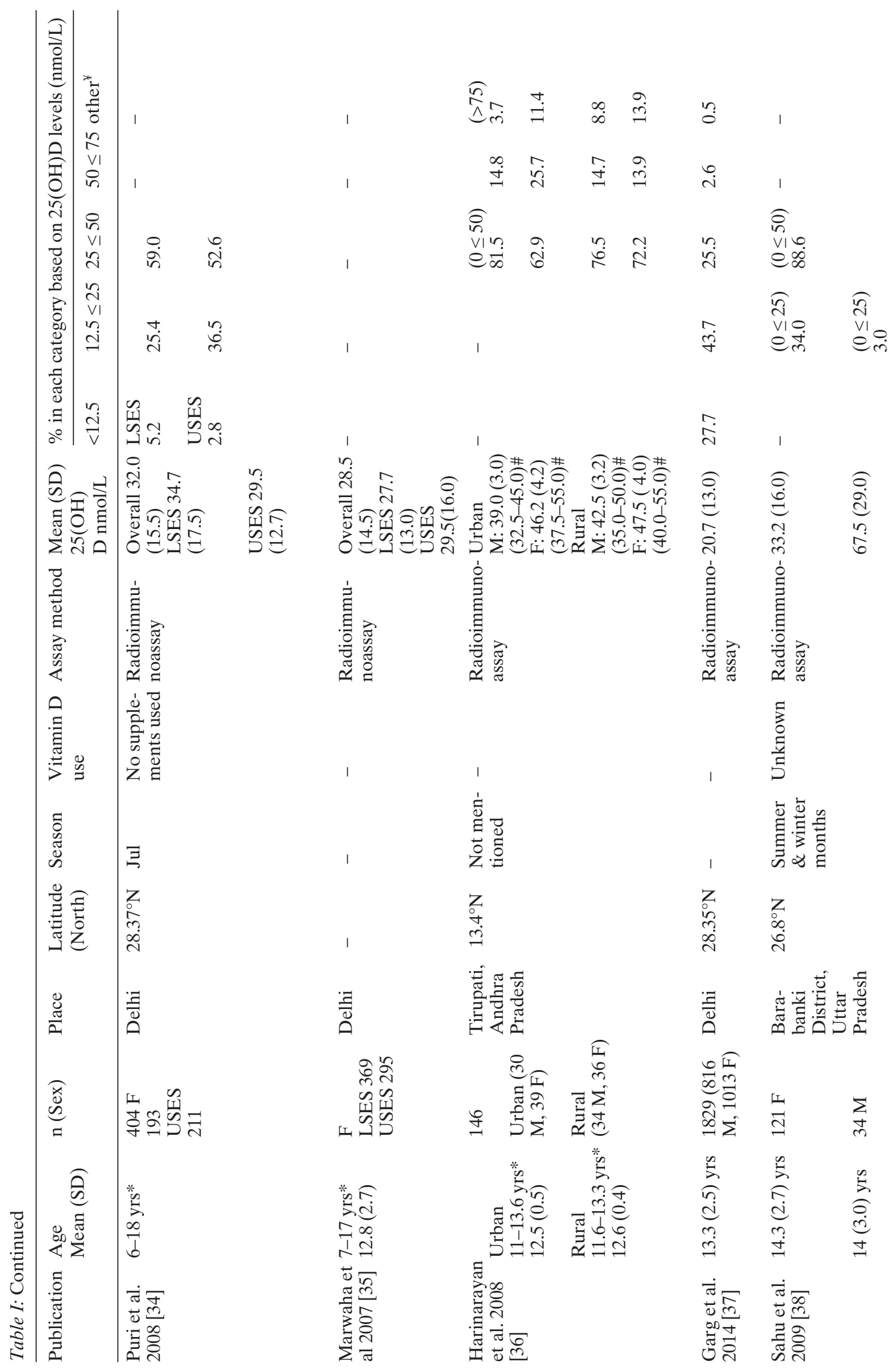


studies included have used different age ranges and age cut-offs, with no clear rationale for selecting the age ranges. In absence of homogeneity in age ranges used by various authors, we have reported all studies covering the age groups from birth to 18 years in Table I, those with participants aged $>18$ years have been reported in Table III, and vitamin D status of pregnant women is shown in Table II.

Both age group and mean ages have been reported in our tables because large age ranges were used in most studies where medians were not calculated and means held little value. We have reported medians wherever available.

Radioimmunoassay was the most commonly used method for assessment of $25(\mathrm{OH}) \mathrm{D}$ in serum or plasma, but a few articles reported using electrochemiluminescense, high performance liquid chromatography (HPLC) and enzyme-linked immunosorbent assay (ELISA). Various assays for determining 25(OH)D levels are available, but standardization and harmonization of these $25(\mathrm{OH}) \mathrm{D}$ measurements is an issue. Serum $25(\mathrm{OH}) \mathrm{D}$ levels vary depending on the assay used [18-21]. To address these issues, many laboratories participate in quality and surveillance programs to enable standardized $25(\mathrm{OH}) \mathrm{D}$ values. None of the studies reported being enrolled in any external quality control program. Most studies reported the vitamin D status as mean 25(OH)D levels while a few used median with interquartile range; those reporting proportions that were vitamin $\mathrm{D}$-deficient used various cut-offs for deficiency. Use of vitamin D supplements is not reported in the majority of studies.

\section{Vitamin D status in infants, children and adolescents}

Table I lists all studies conducted on infants, children, and adolescents arranged in ascending order of age for better understanding. However, different assay methods used, serum 25(OH)D values reported either as medians or as means $25(\mathrm{OH}) \mathrm{D}$, varying cut-offs for deficiency, insufficiency and sufficiency and inconsistent reporting on seasonality and vitamin D use made comparisons of the studies difficult.

The mean values for $25(\mathrm{OH}) \mathrm{D}$ ranged from 17.7 (22.5) nmol/L [31] to 130.5 (67.7) nmol/L [32], showing large variability. Considerable heterogenity was also seen in vitamin D status between studies conducted on the same age group and within the same city, for e.g. mean serum vitamin D levels from Delhi in the first two months after birth ranged between 29.0 (20.7) 


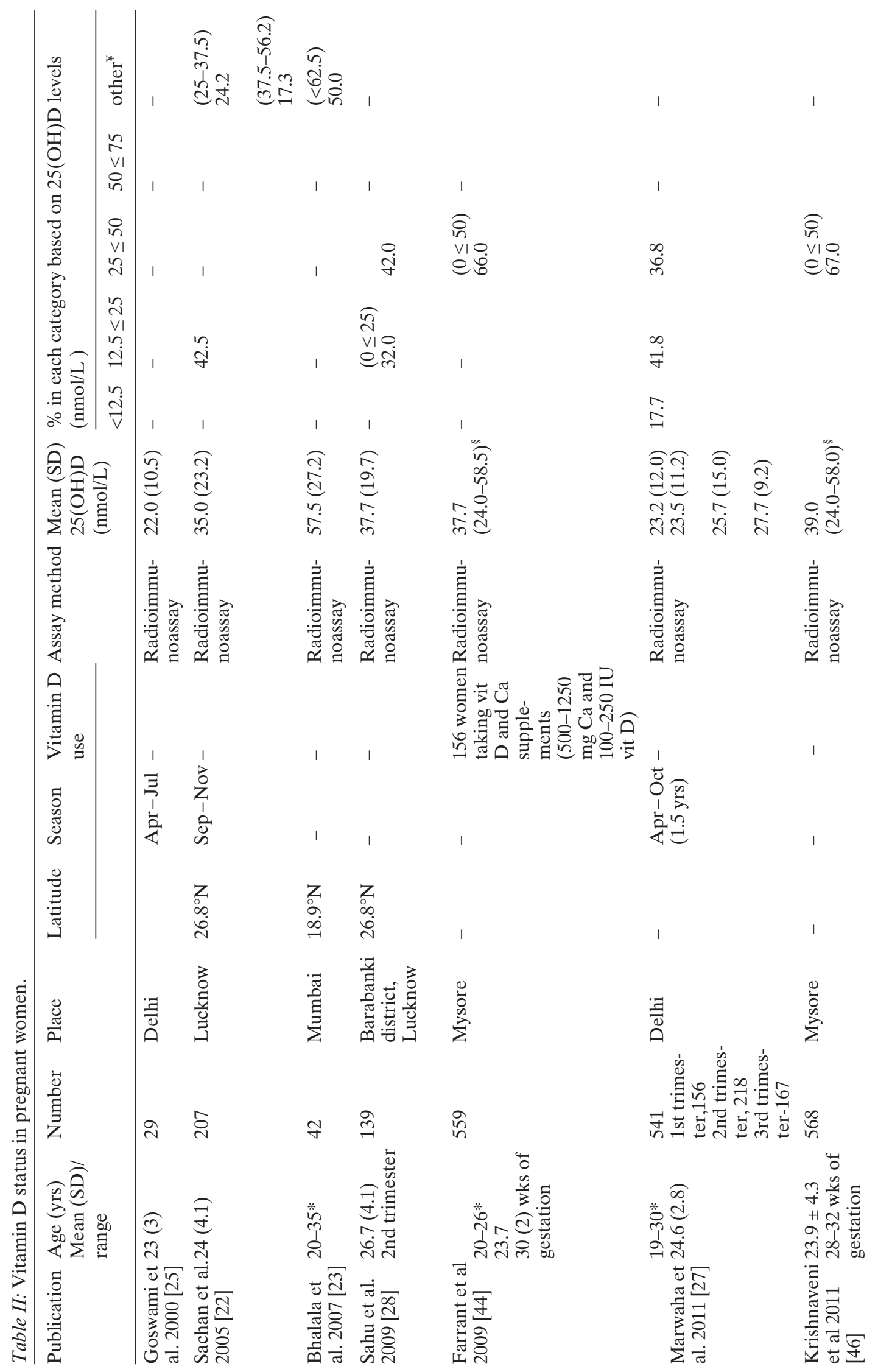




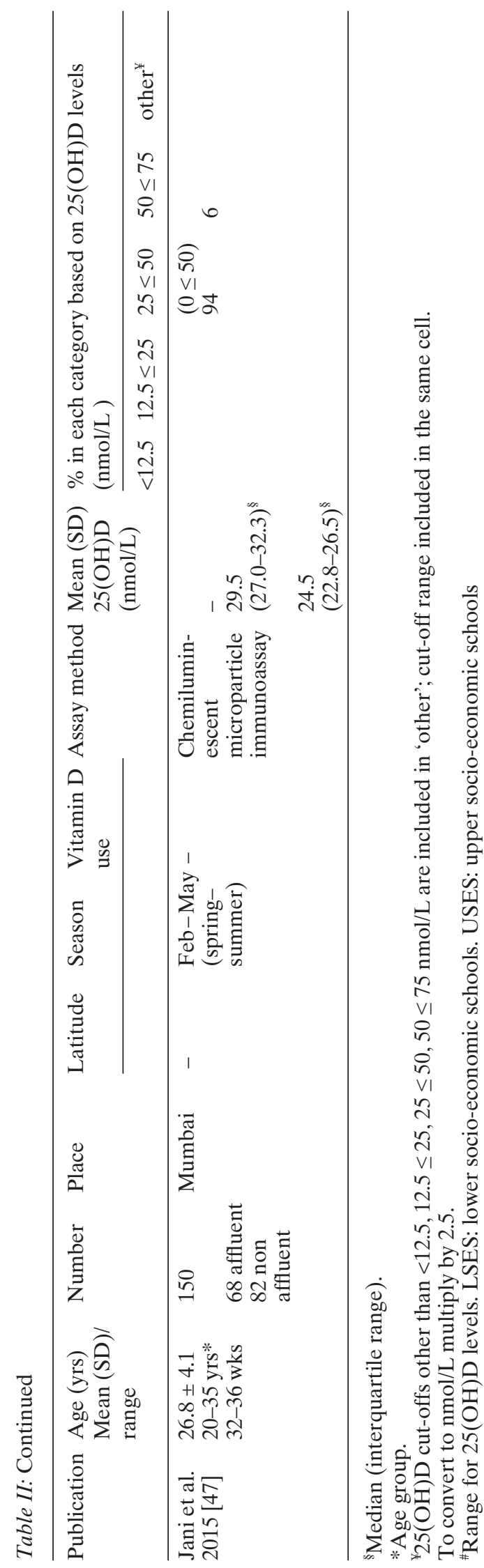

nmol/L [26], 22.2 (10.2) nmol/L [27] and 31.5 (21.0) $\mathrm{nmol} / \mathrm{L}[28]$. Vitamin D status at birth was poor, with nearly $95 \%$ of newborn children having deficient levels of 25(OH)D (mean 25(OH)D below $50 \mathrm{nmol} / \mathrm{L}$; table 1). Pollution appeared to have an appreciable effect on vitamin D levels, with children from less polluted areas having half the levels of mean $25(\mathrm{OH})$ $\mathrm{D}$ when compared those in highly polluted areas [31.0 (17.5) vs $67.7(17.5) \mathrm{nmol} / \mathrm{L}]$ [30]. Living in rural areas [36] as well as playing outdoors rather than staying indoors [32] resulted in better vitamin D status. Seasonal variation in $25(\mathrm{OH}) \mathrm{D}$ levels was observed in most studies that included summer and winter months in their methods $[29,31,38]$, with mean $25(\mathrm{OH}) \mathrm{D}$ levels higher in the summer months. However, none of the authors applied any statistical tests of significance to show the extent of variation due to season.

\section{Vitamin D status of pregnant women}

Vitamin D status of pregnant women is important in India because undernutrition of the mother prior to and during pregnancy is a risk factor for low birth weight, which is common in India. However, the role of vitamin D during pregnancy is not clearly defined $[41,42]$. Vitamin D deficiency in pregnancy has been associated with a spectrum of adverse pregnancy and birth outcomes [43], including gestational diabetes [44], preeclampsia [43] preterm birth [45] as well as cardio-metabolic risks [46]. Little is known about vitamin D status in Indian pregnant women and whatever literature is available is not very consistent. Table 2 gives available data on vitamin $\mathrm{D}$ status of pregnant women in India. The publications covered are from different parts of the country. Eight studies fulfilled our inclusion criteria and were conducted on women aged $19-40$ years.

With a lot of disparity in gestation time, cut-offs of $25(\mathrm{OH}) \mathrm{D}$, season of assessment, as well as mean $25(\mathrm{OH}) \mathrm{D}$ levels, it is difficult to compare data from various studies reported in this article. Mean (SD) 25(OH)D levels ranged from $22.0(10.5)$ to 57.5 (27.2) $\mathrm{nmol} / \mathrm{L}$, and the proportion of women with serum levels of $25(\mathrm{OH}) \mathrm{D}<50 \mathrm{nmol} / \mathrm{L}$ (classified as deficient) varied from 20 to $67 \%$ (Table II).

\section{Vitamin D status of adults and elderly}

A total of 23 studies on healthy adults were shortlisted under this section (Table III). Due to very wide age ranges used by various investigators and some arti- 


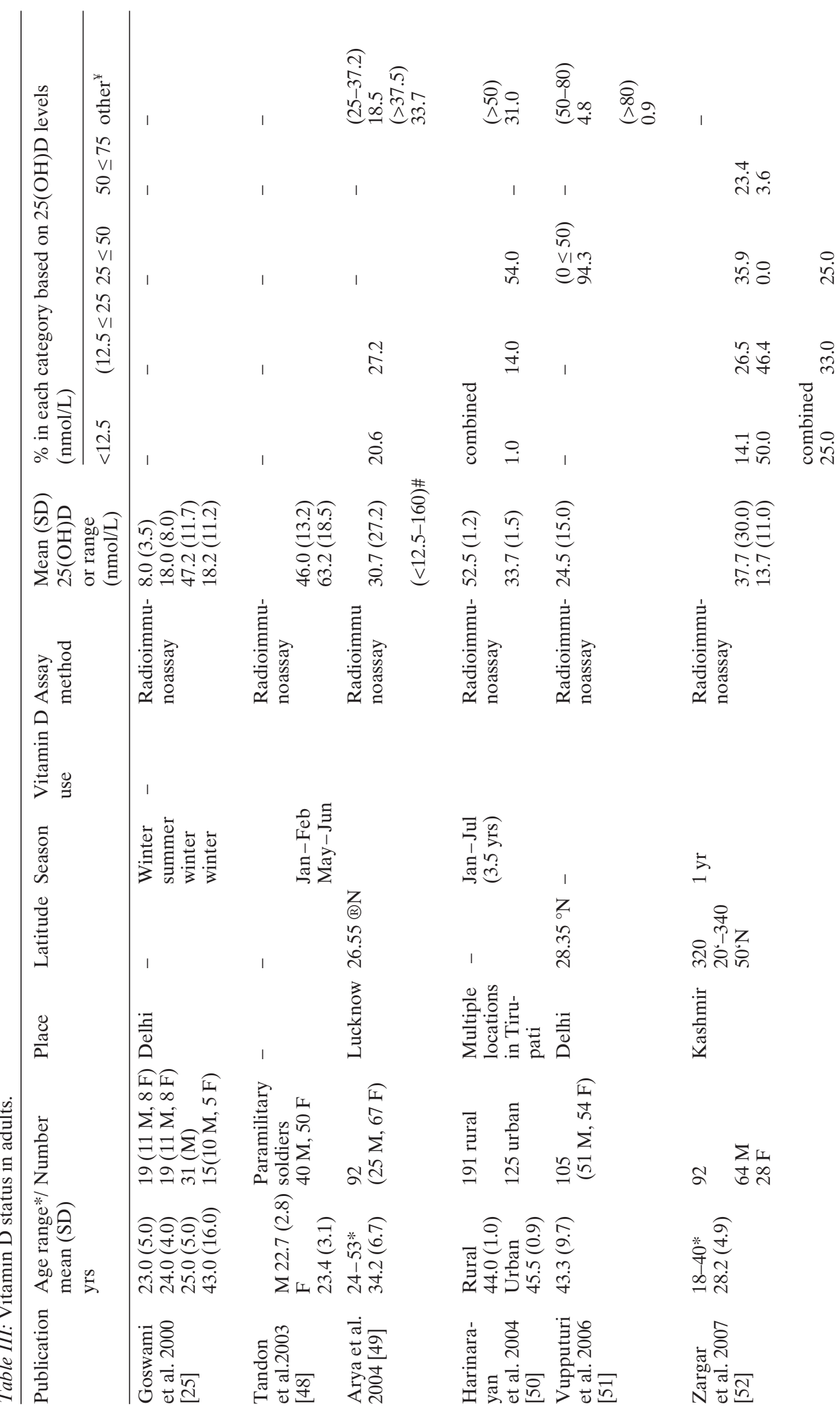




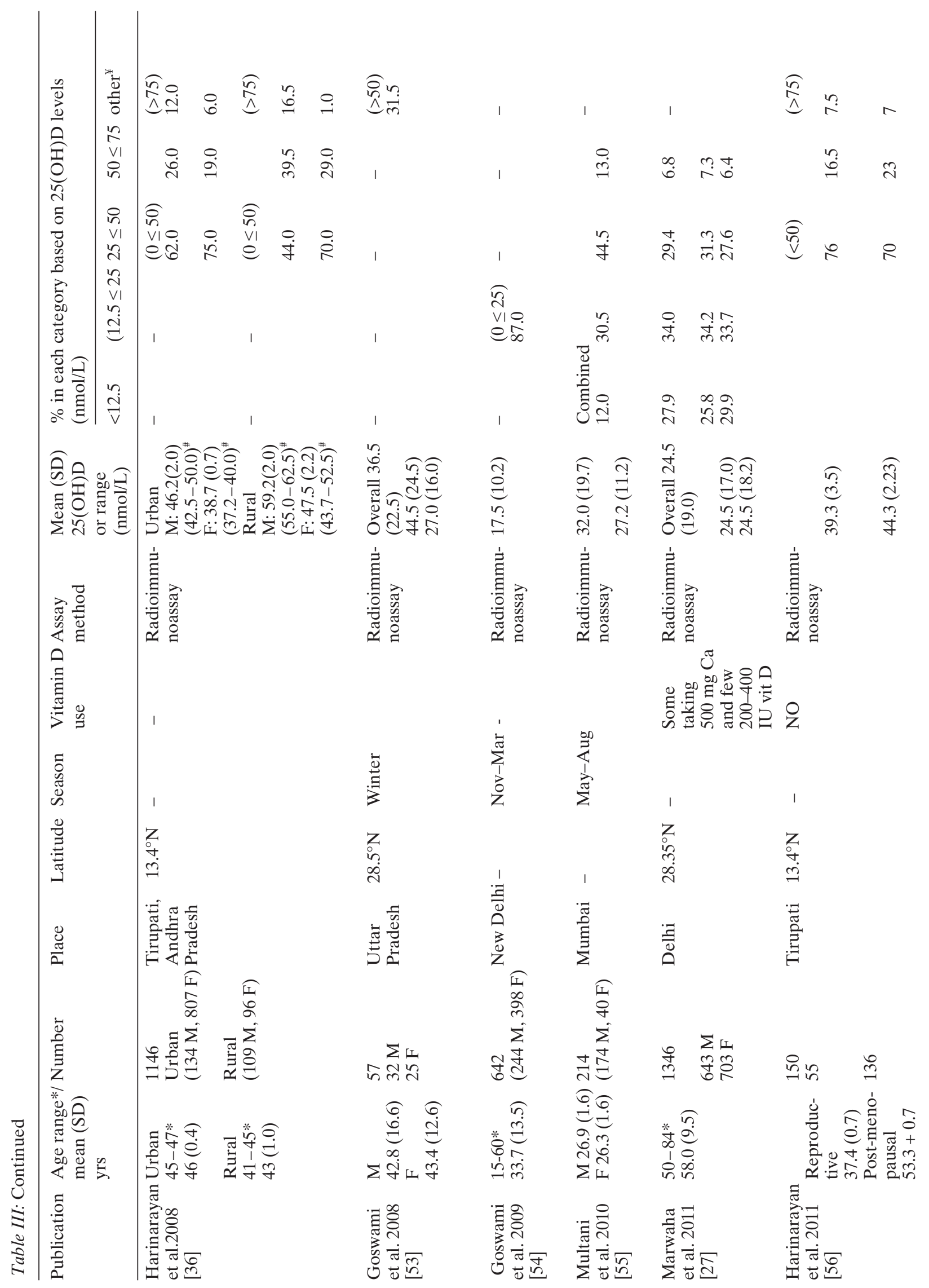




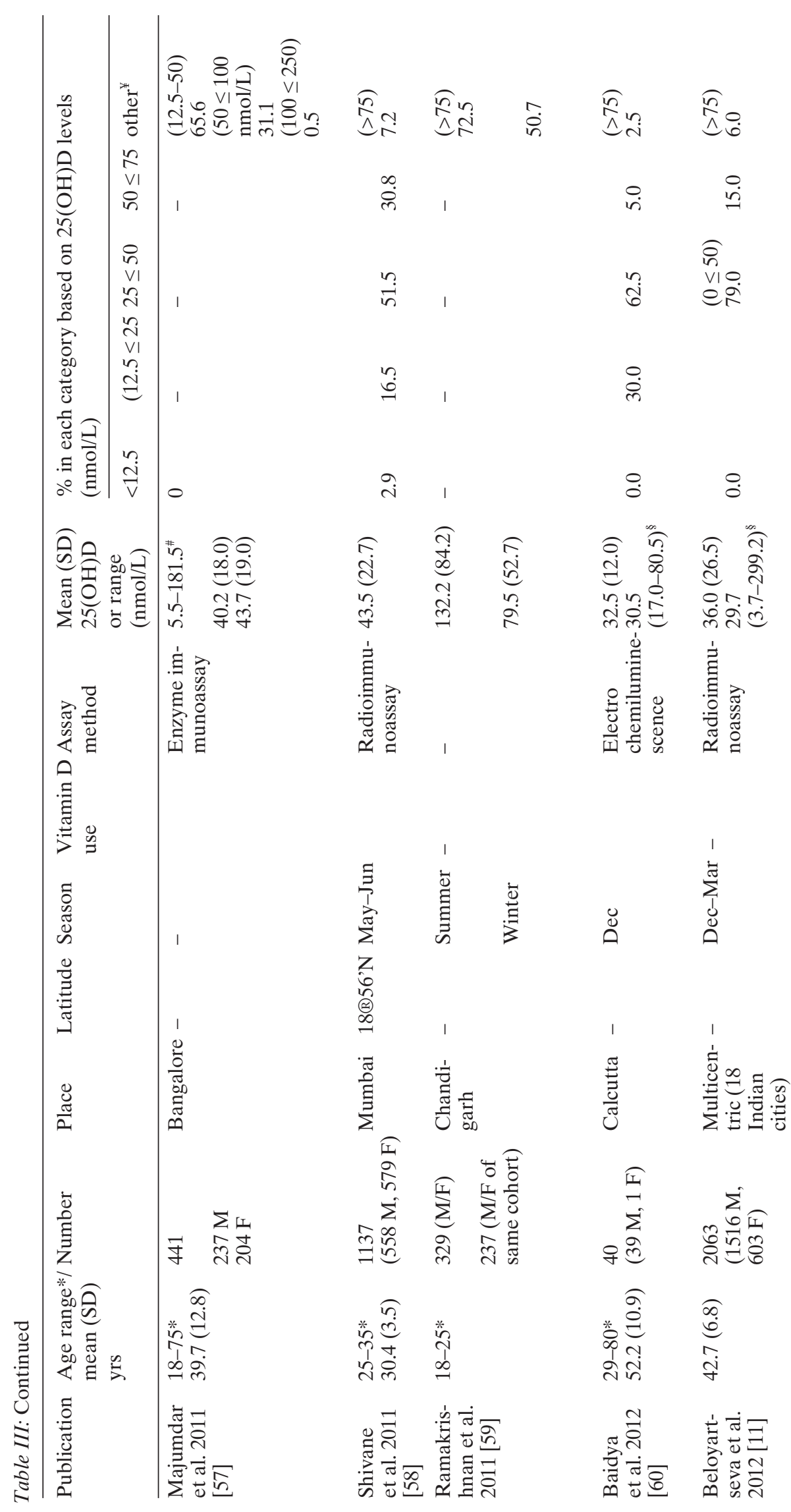




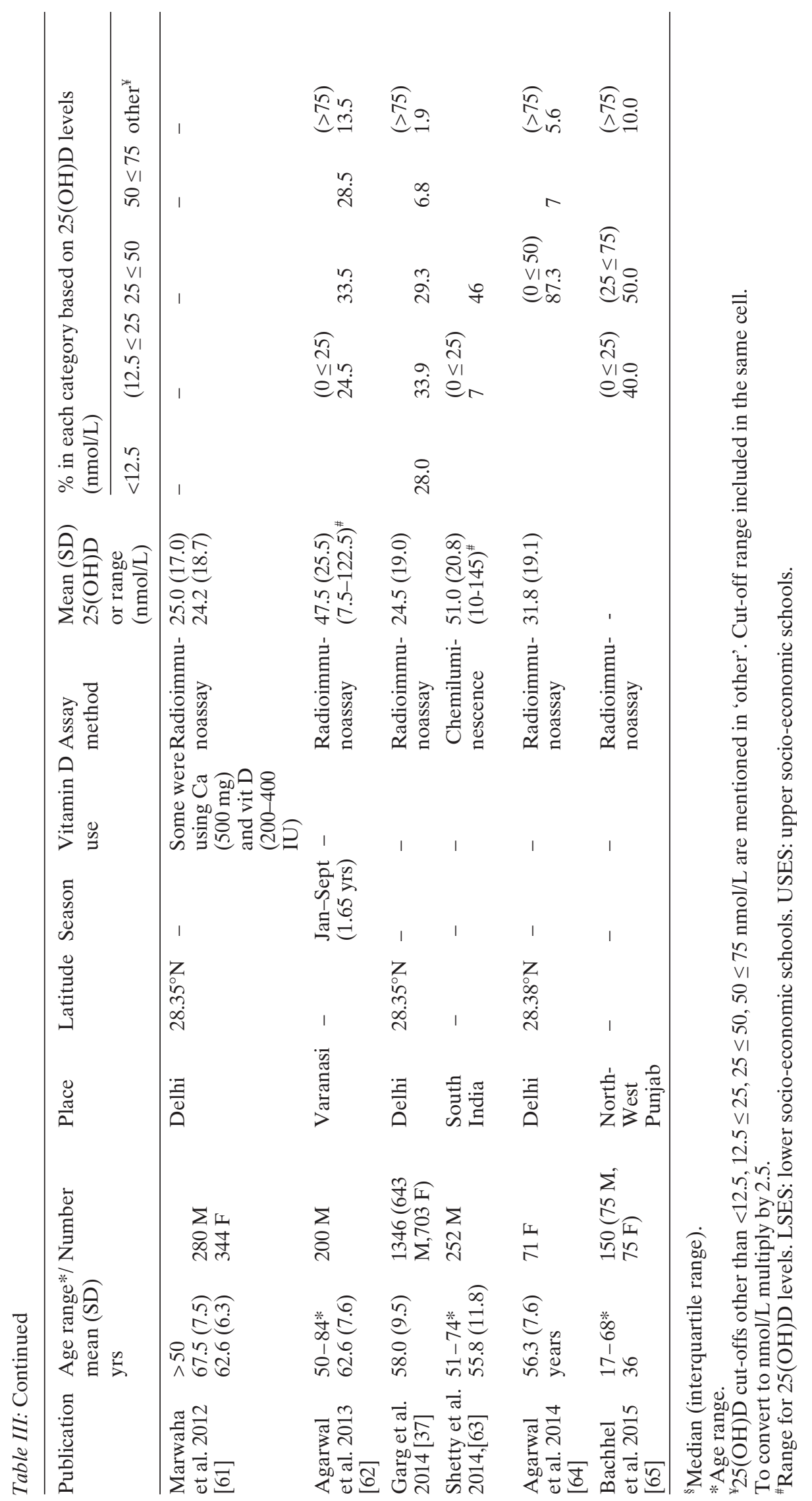


cles including the elderly in adults, data on elderly have been included in this table.

The age ranges included in this table are from 18 to 80 years with most authors reporting either age range or mean age. A few have reported median and interquartile ranges.

Overall mean 25(OH)D levels reported were between $8.0(3.5) \mathrm{nmol} / \mathrm{L}$ [25] and 132.2 (84.2) nmol/L [59]. Mean $25(\mathrm{OH}) \mathrm{D}$ values were higher in males when compared to females, respectively [37.7 (30.0) vs 13.7 (11.0) [52]], [44.5 (24.5) vs 27 (16.0) [53]], [32 (19.7) vs 27.2 (11.2) [55]]. The urban population had lower mean $25(\mathrm{OH}) \mathrm{D}$ when compared to the rural population [33.7 (1.5) vs $52.5(1.2) \mathrm{nmol} / \mathrm{L}]$ [50], and being in the paramilitary forces resulted in higher vitamin $\mathrm{D}$ status both in winter and summer [46.0 (13.2) nmol/L, winter; 63.2 (18.5) nmol/L, summer] [48]. The seasonal variation was also reported to influence vitamin D status in other studies and mean $25(\mathrm{OH}) \mathrm{D}$ values were higher in summer as compared to winter $[25,48,59]$. Proportions of adults deficient or sufficient with respect to vitamin D status were reported based on different cut-offs for deficiency and thus no comparisons could be made.

\section{Discussion}

This is a review of studies conducted in the Indian population to determine the vitamin $\mathrm{D}$ status either assessed by mean or median $25(\mathrm{OH}) \mathrm{D}$ vitamin $\mathrm{D}$ or on the proportions deficient based on various cutoffs. All studies show poor vitamin D status based on mean or median 25(OH)D levels irrespective of age. In absence of an accepted definition of vitamin $\mathrm{D}$ deficiency, we used the cut-offs for deficiency as defined by various authors. We found that vitamin $\mathrm{D}$ deficiency is highly prevalent in India despite being a country which has sunshine throughout the year. However, due to a large variation in vitamin D status in studies conducted within the same city as well as within the same groups and different cut-offs used to define deficiency, it was difficult to draw clear-cut conclusions on the extent of vitamin D deficiency in India.

High prevalence of poor vitamin D status as reported above may be attributed to a combination of factors related to geographical location, urbanization, skin pigmentation, changing lifestyle, diet, religious beliefs, air pollution, use of sunscreen and other ways of sun protection or possibly a genetic predisposition to vitamin $\mathrm{D}$ deficiency reported amongst Asian people [66].
Air pollution due to industrial and vehicular emissions forms a cover and absorbs UV radiation preventing it to reach the earth's surface. Pollution has been shown to effect vitamin D status in India [30] and coupled with darker skin pigmentation of Indians [67] can add to the risk of vitamin D deficiency. This is compounded by the desire for a white skin resulting in use of sunscreens, staying indoors during the day, using umbrellas and covering most of the body parts to protect them from sun exposure. Covering of the face and body parts either due to religious or cultural reasons [68-70], or as a protection from the extreme heat of the sun could be one of the main reasons attributable to the low vitamin D status of Indians. Urbanization has resulted in large-scale migration to cities and living in settlements with small cramped homes with very little sunlight. It has also resulted in change in lifestyle of the middle class and the affluent who stay indoors in air-conditioned homes and offices with no direct exposure to sunlight, leading to poor vitamin $\mathrm{D}$ status.

The main source of vitamin D in India is sun exposure. Diets are very low in vitamin D and currently characterized by absence of vitamin D-fortified foods in India [71]. Oily fish are almost non-existent in the Indian diet and meat, which has vitamin D [72], is consumed by a small proportion of people due to exorbitant costs. Thus, any factor interfering with adequate sun exposure could potentially affect vitamin D status. The sun-protecting behaviour of Indians coupled with the urban lifestyle and limited outdoor activity could be the key determinants for a large proportion of population categorized deficient or insufficient, and this needs further investigation. All deficiency levels, including insufficiency and so-called mild deficiency, can be prevented by focused supplementation, but consumption of supplements in India is not common.

This review provides an overview of studies in which the vitamin D status is reported. However, it has a number of potential limitations. Firstly, most studies were conducted in cities and a larger proportion of them in Delhi, so the results are not representative of the population in the country, where more than half of the population still lives in villages. Secondly, with a country as large as India and covering several latitudes, more data is needed from other parts of the country, especially from the eastern and western states as well as rural areas, to draw inferences. Thirdly, barring a few, almost all studies used radioimmunoassay for assessment of plasma or serum 25(OH)D and large variations were seen between methods and between laboratories using the same methods. Quality control procedures in most studies have not been de- 
scribed and there could be a possibility of imprecision in classifying participants who are deficient. Fourthly, with no data on the amount of sunlight exposure in a country with sun protective behaviour it is difficult to determine whether it is the unavailability of enough UVB light due to pollution or other atmospheric covers or simply a behavioural or lifestyle change that is a determinant for the widespread deficiency. Finally, the different cut-offs used to describe deficiency in each study and the heterogeneity in results make it very difficult to draw clear conclusions on the extent of vitamin D deficiency in India.

\section{Conclusion}

This publication provides an overview of $25(\mathrm{OH}) \mathrm{D}$ status in India. It reveals large gaps of information on vitamin D status of populations living in rural areas and also lacks sufficient data on different age groups. It is, however, evident from the published literature that vitamin D deficiency is common in India and prevalent in all age groups and can be of public health concern. More studies are needed to understand the extent of vitamin D deficiency at the population level and among the important groups at risk so that policy decisions can be made.

\section{Funding}

This work is not supported by funding from any source.

\section{Conflict of interest}

Dr. Manfred Eggersdorfer is employed by DSM Nutritional Products. The other authors have no conflict of interest to declare.

\section{Acknowledgements}

The authors acknowledge the assistance of Kalpana Beesabathuni for her initial help during data collection.

\section{References}

1. Hollick, M.F. (2011) Vitamin D: A D-lightful solution for health. J. Investig. Med. 59, 872-880.
2. Vimaleswaran, K.S., Cavadino, A., Berry, D.J., LifeLines Cohort Study investigators, Jorde, R., Dieffenbach, A.K. et al. (2014) Association of vitamin D status with arterial blood pressure and hypertension risk: a mendelian randomisation study. Lancet Diabetes Endocrinol. 2, 719-729.

3. Zeng, J., Wu, G., Yang, W., Gu, X., Liang, W., Yao, Y. et al. (2015) A serum vitamin d level $<25 \mathrm{nmol} / 1$ pose high tuberculosis risk: a meta-analysis. PLoS One. 10, e0126014.

4. Pludowski, P., Holick, M.F., Pilz, S., Wagner, C.L., Hollis, B.W., Grant, W.B. et al. (2013) Vitamin D effects on musculoskeletal health, immunity, autoimmunity, cardiovascular disease, cancer, fertility, pregnancy, dementia and mortality-a review of recent evidence. Autoimmun. Rev. 12, 976-978.

5. Kumar, G.T., Sachdev, H., Chellani, H., Rehman, A., Singh, V., Arora, H. et al. (2011) Effect of weekly vitamin D supplements to Indian low birth weight term infants on mortality, morbidity, and growth in the first 6 months of life: a randomised controlled trial. Br. Med. J. 342, d2975.

6. Trilok-Kumar, G., Arora, H., Rajput, M., Chellani, H., Singh, V., Raynes, J. et al. (2012) Effect of vitamin D supplementation of low birth weight term Indian infants from birth on cytokine production at 6 months. Eur. J. Clin. Nutr. 66, 746-750.

7. Grant, W.B., Wimalawansa, S.J., Holick, M.F., Cannell, J.J., Pludowski, P., Lappe, J.M. et al. (2015) Emphasizing the health benefits of vitamin $\mathrm{D}$ for those with neurodevelopmental disorders and intellectual disabilities. Nutrients 7, 1538-1564.

8. Hilger, J., Friedel, A., Herr, R., Rausch, T., Roos, F., Wahl, D.A., Pierroz, D.D., Weber, P. and Hoffmann, K. (2014) A systematic review of vitamin D status in populations worldwide. Br. J. Nutr. 111, 23-45.

9. Palacios, C. and Gonzalez, L. (2014) Is vitamin D deficiency a major global public health problem? J Steroid Biochem. Mol. Biol. 144 Pt A, 138-145.

10. Wahl, D.A., Cooper, C., Ebeling, P.R., Eggersdorfer, M., Hilger, J., Hoffmann, K., Josse, R., Kanis, J.A., Mithal, A., Pierroz, D.D., Stenmark, J., Stöcklin, E. and Dawson-Hughes, B. (2012) A global representation of vitamin D status in healthy populations. Arch. Osteoporos. 7, 155-172.

11. Beloyartseva, M., Mithal, A., Kaur, P., Kalra, S., Baruah, M.P., Mukhopadhyay, S. et al. (2012) Widespread vitamin D deficiency among Indian health care professionals. Arch. Osteoporos. 7, $187-192$.

12. Lips, P. (2001) Vitamin D deficiency and secondary hyperparathyroidism in the elderly: consequences for 
bone loss and fractures and therapeutic implications. Endocr. Rev. 22, 477-501.

13. Lips, P., Van Schoor, N.M. and Bravenboer, N. (2013) Vitamin D-Related Disorders. Primer on the Metabolic Bone Diseases and Disorders of Mineral Metabolism. Wiley \& Sons, Hoboken, N.J., USA.

14. Institute of Medicine, F.A.N.B. (2011) Dietary Reference Intakes for Calcium and Vitamin D. National Academies Press, Washington, DC, USA.

15. Ross, A.C., Manson, J.E., Abrams, S.A., Aloia, J F., Brannon, P.M., Clinton, S.K., Durazo-Arvizu, R.A., Gallagher, J.C., Gallo, R.L., Jones, G., Kovacs, C.S., Mayne, S.T., Rosen, C.J. and Shapses, S.A. (2011) The 2011 report on dietary reference intakes for calcium and vitamin D from the Institute of Medicine: What clinicians need to know. J. Clin. Endocrinol. Metab. 96, 53-58.

16. Spedding, S., Vanlint, S., Morris, H. and Scragg, R. (2013) Does vitamin D sufficiency equate to a single serum 25-hydroxyvitamin D level or are different levels required for non-skeletal diseases? Nutrients 5, $5127-5139$.

17. Sohl, E., de Jongh, R.T., Heymans, M.W., van Schoor, N.M., Lips, P. et al. (2015) Thresholds for serum $25(\mathrm{OH}) \mathrm{D}$ concentrations with respect to different outcomes. J. Clin. Endocrinol. Metab. jc20151353.

18. Enko, D., Fridrich, L., Rezanka, E., Stolba, R., Ernst, J., Wendler, I. et al. (2014) 25-hydroxy-vitamin D status: limitations in comparison and clinical interpretation of serum-levels across different assay methods. Clin. Lab. 60, 1541-1550.

19. Abdel-Wareth, L., Haq, A., Turner, A., Khan, S., Salem, A., Mustafa, F. et al. (2013) Total vitamin D assay comparison of the Roche diagnostics "Vitamin D Total" electrochemoluminescence protein binding assay with the chromsystems HPLC method in a population with both D2 and D3 forms of vitamin D. Nutrients 5, 971-980.

20. Farrell, C.J.L., Martin, S., McWhinney, B., Straub, I., Williams, P. and Herrmann, M. (2012) State-of-theart vitamin D assays: A comparison of automated immunoassays with liquid chromatography-tandem mass spectrometry methods. Clin. Chem. 58, $3531-3542$.

21. Wootton, A.M. (2005) Improving the measurement of 25-hydroxyvitamin D. Clin. Biochem. Rev. 26, $33-36$.

22. Sachan, A., Gupta, R., Das, V., Agarwal, A., Awasthi, P.K. and Bhatia, V. (2005) High prevalence of vitamin $\mathrm{D}$ deficiency among pregnant women and their newborns in northern India. Am. J. Clin. Nutr. 81, 1060-1064.
23. Bhalala, U., Desai, M., Parekh, P., Mokal, R. and Chheda, B. (2007) Subclinical hypovitaminosis D among exclusively breastfed young infants. Indian Pediatr. 44, 897-901.

24. Agarwal, R.,Virmani, D., Jaipal, M. L., Gupta, S., Gupta, N., Sankar, M.J., Bhatia, S., Agarwal, A., Devgan, V., Deorari, A. and Paul, V.K. (2012) Vitamin D status of low birth weight infants in Delhi: A comparative study. J. Trop. Pediatr. 58, 446-450.

25. Goswami, R., Gupta, N., Goswami, D., Marwaha, R.K., Tandon, N. and Kochupillai, N. (2000) Prevalence and significance of low 25-hydroxyvitamin D concentrations in healthy subjects in Delhi. Am. J. Clin. Nutr. 72, 472-475.

26. Seth, A., Marwaha, R.K., Singla, B., Aneja, S., Mehrotra, P., Sastry, A., Khurana, M.L., Mani, K., Sharma, B. and Tandon, N. (2009) Vitamin D nutritional status of exclusively breast fed infants and their mothers. J. Pediatr. Endocrinol. Metab. 22, 241-246.

27. Marwaha, R.K., Tandon, N., Chopra, S., Agarwal, N., Garg, M.K., Sharma, B., Kanwar, R. S., Bhadra, K., Singh, S., Mani, K. and Puri, S. (2011) Vitamin $\mathrm{D}$ status in pregnant Indian women across trimesters and different seasons and its correlation with neonatal serum 25-hydroxyvitamin D levels. Br. J. Nutr. 106, $1383-1389$.

28. Agarwal, N., Faridi, M.M., Aggarwal, A. and Singh, O. (2010) Vitamin D Status of term exclusively breastfed infants and their mothers from India. Acta Paediatr. 99, 1671-1674.

29. Jain, V., Gupta, N., Kalaivani, M., Jain, A., Sinha, A. and Agarwal, R. (2011) Vitamin D deficiency in healthy breastfed term infants at 3 months and their mothers in India: seasonal variation \& determinants. Indian J. Med. Res. 133, 267-273.

30. Agarwal, K.S., Mughal, M.Z., Upadhyay, P., Berry, J.L., Mawer, E. B. and Puliyel, J.M. (2002) The impact of atmospheric pollution on vitamin D status of infants and toddlers in Delhi, India. Arch. Dis. Child. 87, 111-113.

31. Tiwari, L. and Puliyel, J.M. (2004) Vitamin D level in slum children of Delhi. Indian Pediatr. 41, 1076-1077.

32. Ekbote, V.H., Khadilkar, A. V., Mughal, M. Z., Hanumante, N., Sanwalka, N., Khadilkar, V. V., Chiplonkar, S.A., Kant, S. and Ganacharya, R. (2010) Sunlight exposure and development of rickets in Indian toddlers. Indian J. Pediatr. 77, 61-65.

33. Ekbote, V.H., Khadilkar, A.V., Chiplonkar, S.A. and Khadilkar, V.V. (2011) Determinants of bone mineral content and bone area in Indian preschool children. J. Bone Miner. Metab. 29, 334-341. 
34. Puri, S., Marwaha, R.K., Agarwal, N., Tandon, N., Agarwal, R., Grewal, K., Reddy, D. H. and Singh, S. (2008) Vitamin D status of apparently healthy schoolgirls from two different socioeconomic strata in Delhi: relation to nutrition and lifestyle. Br. J. Nutr. 99, 876-882.

35. Marwaha, R.K., Tandon, N., Reddy, D.H., Mani, K., Puri, S., Aggarwal, N., Grewal, K. and Singh, S. (2007) Peripheral bone mineral density and its predictors in healthy school girls from two different socioeconomic groups in Delhi. Osteoporos. Int. 18, $375-383$.

36. Harinarayan, C.V., Ramalakshmi, T., Prasad, U.V. and Sudhakar, D. (2008) Vitamin D status in Andhra Pradesh: a population based study. Indian J. Med. Res.127, 211-218.

37. Garg, M.K., Tandon, N., Marwaha, R.K., Menon, A.S. and Mahalle, N. (2014) The relationship between serum 25-hydroxy vitamin $\mathrm{D}$, parathormone and bone mineral density in Indian population. Clin. Endocrinol. 80, 41-46.

38. Sahu, M., Bhatia, V., Aggarwal, A., Rawat, V., Saxena, P., Pandey, A. and Das, V. (2009) Vitamin $\mathrm{D}$ deficiency in rural girls and pregnant women despite abundant sunshine in northern India. Clin. Endocrinol. 70, 680-684.

39. Khadilkar, A.V., Crabtree, N.J., Ward, K.A., Khadilkar, V.V., Shaw, N.J. and Mughal, M.Z (2010) Bone status of adolescent girls in Pune (India) compared to age matched South Asian \& white Caucasian UK girls. Osteoporos. Int. 21, 1155-1160.

40. Marwaha, R.K., Tandon, N., Reddy, D.R., Aggarwal, R., Singh, R., Sawhney, R.C., Saluja, B., Ganie, M.A and Singh, S. (2005) Vitamin D and bone mineral density status of healthy school children in northern India. Am. J. Clin. Nutr. 82, 477-482.

41. Hollis, B.W., Johnson, D., Hulsey, T.C., Ebeling, M. and Wagner, C.L. (2011) Vitamin D supplementation during pregnancy: double-blind, randomized clinical trial of safety and effectiveness. J. Bone Miner. Res. 26, 2341-2357.

42. Thorne-Lyman, A. and Fawzi, W.W. (2012) Vitamin $\mathrm{D}$ during pregnancy and maternal, neonatal and infant health outcomes: a systematic review and meta-analysis Paediatr. Perinat. Epidemiol. 26, Doi: 10.1111/j.1365-3016.2012.01283.x

43. Wei, S.Q. (2014) Vitamin D and pregnancy outcomes. Curr. Opin. Obstet. Gynecol. 26, 438-447.

44. Farrant, H.J., Krishnaveni, G.V., Hill, J.C., Boucher, B.J., Fisher, D. J., Noonan, K., Osmond, C., Veena, S.R. and Fall, C.H. (2009) Vitamin D insufficiency is common in Indian mothers but is not associated with gestational diabetes or variation in newborn size. Eur. J. Clin. Nutr. 63, 646-652.

45. Wagner, C.L., Baggerly, C., McDonnell, S.L., Baggerly, L., Hamilton, S.A., Winkler, J. et al. (2015) Post-hoc comparison of vitamin D status at three time points during pregnancy demonstrates lower risk of preterm birth with higher vitamin $\mathrm{D}$ closer to delivery. J. Steroid Biochem. Mol. Biol. 148, 256-260.

46. Krishnaveni, G.V., Veena, S.R., Winder, N.R., Hill, J.C., Noonan, K., Boucher, B.J., Karat, S. C. and Fall, C.H. (2011) Maternal vitamin D status during pregnancy and body composition and cardiovascular risk markers in Indian children: the Mysore Parthenon Study. Am. J. Clin. Nutr. 93, 628-635.

47. Jani, R., Palekar, S., Munipally, T., Ghugre, P. and Udipi, S. (2015) Widespread 25-hydroxyvitamin $\mathrm{D}$ deficiency in affluent and nonaffluent pregnant Indian women. Biomed. Res. Int. 2014, 892162.

48. Tandon, N., Marwaha, R.K., Kalra, S., Gupta, N., Dudha, A. and Kochupillai, N. (2003) Bone mineral parameters in healthy young Indian adults with optimal vitamin D availability. Natl. Med. J. 16, 298-302.

49. Arya, V., Bhambri, R., Godbole, M.M. and Mithal, A. (2004) Vitamin D status and its relationship with bone mineral density in healthy Asian Indians. Osteoporos. Int.15, 56-61.

50. Harinarayan, C.V., Ramalakshmi, T. and Venkataprasad, U. (2004) High prevalence of low dietary calcium and low vitamin D status in healthy south Indians. Asia Pac. J. Clin. Nutr. 13, 359-364.

51. Vupputuri, M.R., Goswami, R., Gupta, N., Ray, D., Tandon, N. and Kumar, N. (2006) Prevalence and functional significance of 25-hydroxyvitamin D deficiency and vitamin D receptor gene polymorphisms in Asian Indians. Am. J. Clin. Nutr. 83, 1411-1419.

52. Zargar, A.H., Ahmad, S., Masoodi, S.R., Wani, A.I., Bashir, M.I., Laway, B.A. and Shah, Z. A. (2007) Vitamin D status in apparently healthy adults in Kashmir Valley of Indian subcontinent. Postgrad. Med. J. 83, 713-716.

53. Goswami, R., Kochupillai, N., Gupta, N., Goswami, D., Singh, N. and Dudha, A. (2008) Presence of $25(\mathrm{OH}) \mathrm{D}$ deficiency in a rural North Indian village despite abundant sunshine. J. Assoc. Physicians India $56,755-757$.

54. Goswami, R., Marwaha, R.K., Gupta, N., Tandon, N., Sreenivas, V., Tomar, N., Ray, D., Kanwar, R. and Agarwal, R. (2009) Prevalence of vitamin $\mathrm{D}$ deficiency and its relationship with thyroid autoimmunity in Asian Indians: a community-based survey. Br. J. Nutr. 102, 382-386. 
55. Multani, S.K.,Sarathi, V., Shivane, V., Bandgar, T.R., Menon, P.S. and Shah, N.S. (2010) Study of bone mineral density in resident doctors working at a teaching hospital. J. Postgrad. Med. 56, 65-70.

56. Harinarayan, C.V., Sachan, A., Reddy, P.A., Satish, K.M., Prasad, U.V. and Srivani, P. (2011) Vitamin $\mathrm{D}$ status and bone mineral density in women of reproductive and postmenopausal age groups: a cross-sectional study from south India. J. Assoc. Physicians India 59,698-704.

57. Majumdar, V., Nagaraja, D. and Christopher, R. (2011) Vitamin D status and metabolic syndrome in Asian Indians. Int. J. Obes. 35, 1131-1134.

58. Shivane, V. K., Sarathi, V., Bandgar, T., Menon, P. and Shah, N. (2011) High prevalence of hypovitaminosis $\mathrm{D}$ in young healthy adults from the western part of India. Postgrad. Med. J. 87, 514-518.

59. Ramakrishnan, S., Bhansali, A., Bhadada, S.K., Sharma, R., Walia, R., Ravikiran, M., Shanmugasundar, G. and Ravikumar, P. (2011) Vitamin D status and its seasonal variability in healthy young adults in an Asian Indian urban population. Endocr. Pract.17, 185-191.

60. Baidya, A., Chowdhury, S., Mukhopadhyay, S., Ghosh, S. (2012) Profile of vitamin D in a cohort of physicians and diabetologists in Kolkata. Indian J. Endocrinol. Metab. 16, S416-S417.

61. Marwaha, R.K., Tandon, N., Gupta, Y., Bhadra, K., Narang, A., Mani, K., Mithal, A. and Kukreja, S. (2012) The prevalence of and risk factors for radiographic vertebral fractures in older Indian women and men: Delhi Vertebral Osteoporosis Study (DeVO). Arch. Osteoporos.7, 201-207.

62. Agarwal, N. and Sharma, B. (2013) Prevalence of osteoporosis in otherwise healthy Indian males aged 50 years and above. Arch. Osteoporos. 8, 116.

63. Shetty, S., Kapoor, N., Naik, D., Asha, H.S., Prabu, S., Thomas, N., Seshadri, M.S. and Paul, T.S. (2014) Osteoporosis in healthy South Indian males and the influence of life style factors and vitamin D status on bone mineral density. J. Osteoporos. 2014, 723238.

64. Agarwal, N., Mithal, A., Kaur, P., Dhingra, V., Godbole, M.M. and Shukla, M. (2014) Vitamin D and insulin resistance in postmenopausal Indian women. Indian J. Endocrinol. Metab. 18, 89-93.
65. Bachhel, R., Singh, N.R. and Sidhu, J.S. (2015) Prevalence of vitamin D deficiency in north-west Punjab population: A cross-sectional study. Int. J. Appl. Basic Med. Res. 5, 7-11.

66. Shaw, N.J. and Pal, B.R. (2002) Vitamin D deficiency in UK Asian families: activating a new concern. Arch. Dis. Child. 86, 147-149.

67. Clemens, T.L., Adams, J.S., Henderson, S.L. and Holick, M.F. (1982) Increased skin pigmentation reduces the capacity of skin to synthesize vitamin D3. Lancet 1, 74-76.

68. Das, G., Crocombe, S., McGrath, M., Berry, J.L. and Mughal, M.Z. (2006) Hypovitaminosis D among healthy adolescent girls attending an inner city school. Arch. Dis. Child. 91, 569-572.

69. Dijkstra, S.H., Van Beek, A., Janssen, J.W., de Vleeschouwer, L.H., Huysman, W.A. and Van Den Akker, E.L. (2007) High prevalence of vitamin D deficiency in newborns of high-risk mothers. Arch. Dis. Child. Fetal Neonatal Ed. 92, 750-753.

70. Van der Meer I.M., Karamali, N.S., Boeke, A.J., Lips, P., Middelkoop, B.J., Verhoeven I. and Wuister, J.D. (2006) High prevalence of vitamin D deficiency in pregnant non-Western women in The Hague, Netherlands. Am. J. Clin. Nutr. 84, 350-353.

71. Babu, U.S. and Calvo, M.S. (2010) Modern India and the vitamin D dilemma: evidence for the need of a national food fortification program. Mol. Nutr. Food Res. 54, 1134-1147.

72. Crowe, F.L., Steur, M., Allen, N.E., Appleby, P.N., Travis, R.C., Key and T.J. (2011) Plasma concentrations of 25-hydroxyvitamin D in meat eaters, fish eaters, vegetarians and vegans: results from the EPIC-Oxford study. Public Health Nutr. 14, 340-346.

Geeta Trilok Kumar
Department of Biochemistry
Institute of Home Economics
University of Delhi
F-4 Hauz Khas Enclave
Delhi 110016
India
Tel.: +911146018108
Fax: +911126510711
geetatrilokkumar@gmail.com 